\title{
POST-FIRE FORESTRY RECOVERY MONITORING USING HIGH-RESOLUTION MULTISPECTRAL IMAGERY FROM UNMANNED AERIAL VEHICLES
}

\author{
L. Pádua ${ }^{1,2}$, T. Adão ${ }^{1,2}$, N. Guimarães ${ }^{1}$, A. Sousa ${ }^{1,2}$, E. Peres ${ }^{1,2}$, J. J. Sousa ${ }^{1.2}$ \\ ${ }^{1}$ Engineering Department, School of Science and Technology, University of Trás-os-Montes e Alto Douro, Vila Real, Portugal - \\ (luispadua, telmoadao, nsguimaraes, amrs, eperes, jjsousa)@utad.pt \\ ${ }^{2}$ Centre for Robotics in Industry and Intelligent Systems (CRIIS), INESC Technology and Science (INESC-TEC), Porto, Portugal
}

\section{Commission VI, WG VI/4}

KEY WORDS: Post-fire management, forest regeneration, fire severity, unmanned aerial vehicles, photogrammetric processing, multispectral imagery, digital image processing

\begin{abstract}
:
In recent years unmanned aerial vehicles (UAVs) have been used in several applications and research studies related to environmental monitoring. The works performed have demonstrated the suitability of UAVs to be employed in different scenarios, taking advantage of its capacity to acquire high-resolution data from different sensing payloads, in a timely and flexible manner. In forestry ecosystems, UAVs can be used with accuracies comparable with traditional methods to retrieve different forest properties, to monitor forest disturbances and to support disaster monitoring in fire and post-fire scenarios. In this study an area recently affected by a wildfire was surveyed using two UAVs to acquire multi-spectral data and RGB imagery at different resolutions. By analysing the surveyed area, it was possible to detect trees, that were able to survive to the fire. By comparing the ground-truth data and the measurements estimated from the UAV-imagery, it was found a positive correlation between burned height and a high correlation for tree height. The mean NDVI value was extracted used to create a three classes map. Higher NDVI values were mostly located in trees that survived that were not/barely affected by the fire. The results achieved by this study reiterate the effectiveness of UAVs to be used as a timely, efficient and cost-effective data acquisition tool, helping for forestry management planning and for monitoring forest rehabilitation in post-fire scenarios.
\end{abstract}

\section{INTRODUCTION}

Fires, caused by human or natural actions, are one of the disturbances that can severely affect forest ecosystems (Foster et al., 1998). Other major disturbance impacts on forests can result from drought, introduced species, insect and pathogens, hurricanes, windstorms, ice storms, and landslides (Dale et al., 2001). Climate change directly affects fire disturbances through fuel moisture, ignition (lightning activity) and fire spread (wind speed) and indirect affects vegetation productivity, composition and structure (Seidl et al., 2017). These events tend to become more frequent due to lower precipitation levels and higher air temperatures (Camia et al., 2017).

Remote sensing platforms appear as a capable tool for mapping burned areas, evaluate characteristics of active fires, and characterize post-fire ecological effects and forest regeneration (Lentile et al., 2006). Satellite data are a quick way to evaluate forest regeneration in post-fire areas, as shown in several studies (Chu and Guo, 2014; Clemente et al., 2009; Eidenshink et al., 2007; Van Leeuwen, 2008). However, despite the great utility of satellite-based data to characterize a regional scale of burned, some applications require significant higher resolutions, making unmanned aerial vehicles (UAVs) a valuable RS platform to acquire different type of data in a flexible way (Pádua et al., 2017). In forestry, UAVs are used for estimation of dendrometric parameters, tree species classification, canopy gap analysis, forest health monitoring, disease mapping, for forest fire monitoring and post-fire monitoring (Torresan et al., 2017). Such applications are possible due to the flexibility of UAVs to support different sensors enabling to acquire RGB, multispectral, thermal infrared, hyperspectral and LiDAR data providing greater spatial and temporal resolutions than other remote sensing platforms
(Pádua et al., 2017). Indeed, UAVs can be used for forest fire prevention (Fernández-Álvarez et al., 2019), to estimate canopy fuels (Shin et al., 2018), for fire monitoring (Martínez-de Dios et al., 2011; Merino et al., 2012) and to help in firefighting operations (Yuan et al., 2015).

In what concerns studies using UAV-based imagery in post-fire monitoring, some of them where conducted with different purposes. In Fernández-Guisuraga et al. (2018) the suitability of using UAV-based multispectral imagery was shown by surveying a large burned area of 3000 ha, being the UAV-based data presented more information in terms of spatial variability in heterogeneous burned areas in comparison with satellite data. The authors concluded that the acquired high-resolution multispectral data be used for post-fire decision making and interpretation of fine-scale ground patterns. Fraser et al. (2017) acquired RGB using a low-cost UAV to calibrate satellite-based burn severity indices. Larrinaga and Brotons (2019) evaluated the usage of a cost-effective UAS to assess post-fire recovery. The authors used the acquired imagery in typical a photogrammetric processing pipeline to obtain the canopy height models (CHMs) and to evaluate different vegetation indices. The methods employed in this study enabled to estimate the diameter at breast height $(\mathrm{DBH})$ by regression of the CHM and the vegetation indices. This study shows that low-cost UAVs can improve forest monitoring after disturbance, even when there is a limitation of resources. McKenna et al. (2017) generated fire severity maps using UAV-based RGB vegetation indices, by comparing preand post-fire outcomes and classifying the fire severity in the studied high, low and unburnt areas. Likewise, (CarvajalRamírez et al., 2019) conducted a similar study using a multispectral imagery. (Aicardi et al., 2016) assessed forest recovery dynamics using a fixed-wing $\mathrm{UAV}$, in 2015 , to generate 
a DSM that was compared with an ALS-DSM, acquired in 2008. The authors verified that height increases were caused by resprouting of the European aspen (Populus tremula L.) while height decreases were due to logging activities and fall of snags. White et al. (2018) evaluated the potential of jake pine (Pinus banksiana) saplings identification in post-fire environments using UAV-based multispectral imagery. As seen, post-fire monitoring of forested areas using UAVs is an important subject with studies being conducted in different areas of the world. This way, the goal of this study is to demonstrate the suitability of UASs to monitor an area recently affected by a fire by employing fixed-wing and multi-rotor UAVs with RGB and multispectral sensors, to assess the restoration of the area and to evaluate the suitability of the acquired data acquired from different flight heights in the analysis of the remaining trees and snags.

The following section presents the study area and describes the carried-out UAV flights, the imagery type acquired and the data processing methods used in this study. In Section 3 the obtained results are presented and discussed. Finally, in Section 4, the main conclusions and some future developments are pointed out.

\section{MATERIALS AND METHODS}

\subsection{Study area}

The study area is located in the north-eastern region of Portugal, within the municipality of Sabrosa $\left(41^{\circ} 20^{\prime} 40.4^{\prime \prime} \mathrm{N}, 7^{\circ} 36^{\prime} 04.5^{\prime \prime} \mathrm{W}\right)$. This area was severely affected by a wildfire in August 2017. The area has a warm and temperate climate, the average annual temperature is $13.1{ }^{\circ} \mathrm{C}$, while annual precipitation averages 1139 mm. July and August are the months with higher mean temperatures $\left(21{ }^{\circ} \mathrm{C}\right)$ and lower precipitation $(28 \mathrm{~mm})$. The estimated burned area is greater than 200 ha, mostly affecting forested areas of Pinus pinaster but also houses, wood storage buildings, agricultural structures and vehicles. Due to the proximity of a motorway its traffic was stopped both for security and to firefighting reasons. About 230 operators and 60 vehicles have been mobilized for this fire. Subsequently to this disturbance event, logging operations took place to remove burned trees.

\subsection{UAV-based imagery acquisition}

Two different UASs were used in this study to acquire RGB and multispectral imagery in July 2019. A fixed-wing UAV, the senseFly eBee (senseFly SA, Lausanne, Switzerland), that was used to acquire both RGB and multispectral imagery and a costeffective multi-rotor UAV, the DJI Phantom 4 (DJI, Shenzhen, China) used for RGB imagery acquisition only. The fixed-wing solution was considered due to its single-flight coverage range and autonomy. In turn, the multi-rotor UAV was used to survey smaller areas to acquire high-resolution imagery. Both UASs can be used for autonomously carry out flights over a user-defined area. The sensors used, in eBee were the Canon IXUS 127 HS with 16.1 MP resolution, used for RGB imagery acquisition, and the Parrot SEQUOIA, for multispectral imagery acquisition, composed of a four-camera array with $1.2 \mathrm{MP}$ resolution acquiring green $(530-570 \mathrm{~nm})$, red $(640-680 \mathrm{~nm})$, red edge $(730$ $740 \mathrm{~nm})$ and near infrared (NIR) $(770-810 \mathrm{~nm})$ imagery. The radiometric calibration was performed using the provided target prior to the flight. As for the Phantom 4 its $12.4 \mathrm{MP}$ embedded RGB camera was used. Table 1 summarizes the different flights performed. In total, four flights were carried out. The area covered with the eBee was 230 ha for the RGB flight and 160 ha for the multispectral flight, while the two flights performed with the Phantom 4 were 52 ha and 26 ha for the $100 \mathrm{~m}$ and $60 \mathrm{~m}$ flight height, respectively.

\begin{tabular}{|c|c|c|c|c|c|}
\hline \multicolumn{2}{|c|}{ UAV } & \multicolumn{2}{|c|}{ eBee } & \multicolumn{2}{|c|}{ Phantom 4} \\
\hline \multicolumn{2}{|c|}{ Sensor type } & RGB & MSP & RGB & RGB \\
\hline \multicolumn{2}{|c|}{ Flight height (m) } & 425 & 215 & 100 & 60 \\
\hline \multicolumn{2}{|c|}{ GSD $(\mathrm{cm})$} & 12 & 26 & 4.5 & 3 \\
\hline \multirow{2}{*}{$\begin{array}{c}\text { Overlap } \\
(\%)\end{array}$} & Front & 80 & 75 & 75 & 75 \\
\hline & Side & 60 & 60 & 65 & 60 \\
\hline \multicolumn{2}{|c|}{ No. of images } & 91 & 260 & 309 & 410 \\
\hline
\end{tabular}

Table 1. Overall characteristics of the performed flights.

\subsection{Data processing}

The acquired imagery was subjected to photogrammetric processing using the Pix4Dmapper Pro version 4.4.12 (Pix4D SA, Lausanne, Switzerland) which is capable to identify common tie points into the imagery accordingly to its geolocation and internal and external camera parameters, enabling the computation of 3D dense point clouds that can be further used to obtain orthorectified outcomes. In the scope of this study the following outcomes were generated: RGB orthophoto mosaics, digital surface models (DSMs), digital terrain models (DTMs), and vegetation indices.

Each orthorectified outcome driven from the photogrammetric processing was used with different purposes: the orthophoto mosaics for visual inspection of the study area; the DSM to obtain the altitude of the features present at the terrain level; the DTM to estimate the terrain altitude by removing the height of the features present in the area; and vegetation indices to compute the normalized difference vegetation index (NDVI) (Rouse et al., 1974) from the multispectral imagery using the reflectance from NIR and red bands. Moreover, using QGIS, an open source geographic information system, canopy height models (CHMs) were generated by subtracting the DTM to its corresponding DSM, providing, this way, the height of objects above the terrain level (Popescu, 2007).

\subsection{Data analysis}

The orthorectified outcomes produced from the photogrammetric processing of the imagery obtained in each carried flight were used to assess the current status of the surveyed area. This way, the three RGB flights, performed at different flight heights, resulted into different GSD outputs. Two profiles were computed and compared to assess the estimated height differences in the generated DSMs and CHMs.

Moreover, the height of 35 trees were measured in the field over two different areas. These areas were selected due to both area accessibility and representativity of the trees in the study area. The trees were classified into three types: (1) not affected by the fire $-\mathrm{s}$ trees without/low symptoms of being affected by the fire, presenting a complete canopy; (2) partially burned by the fire being trees that were affected by the fire but presented some foliage; and (3) burned by the fire - corresponding to trees completely burned and not presenting any symptoms of restoration. A visual example of this classification is presented in Figure 1. From the 35 analysed trees, 13 were classified as not affected, 6 as partially affected and 16 as burned. This validation was conducted in the flights carried out with the Phantom 4, at $100 \mathrm{~m}$ and $60 \mathrm{~m}$ height, and the coefficient of determination $\left(R^{2}\right)$ 
and root mean square error (RMSE) were evaluated for each defined class.

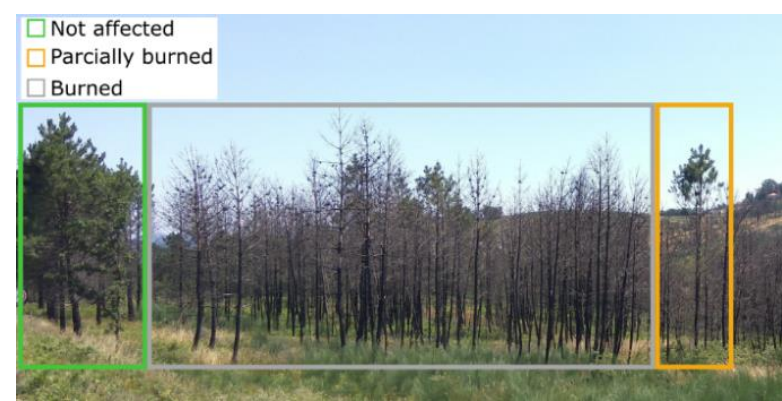

Figure 1. Different types of tree health condition considered in this study.

\section{RESULTS AND DISCUSSION}

The orthophoto mosaic covering the entire analysed are, obtained from fixed-wing flight, is presented in Figure 2. As it can be seen, some trees in the middle part of the study area resisted to the fire, those are mainly located in a riparian zone. It is also noticed, from Figure 2, that some logging operations took place after fire event and that agricultural practices continued in some terrains.

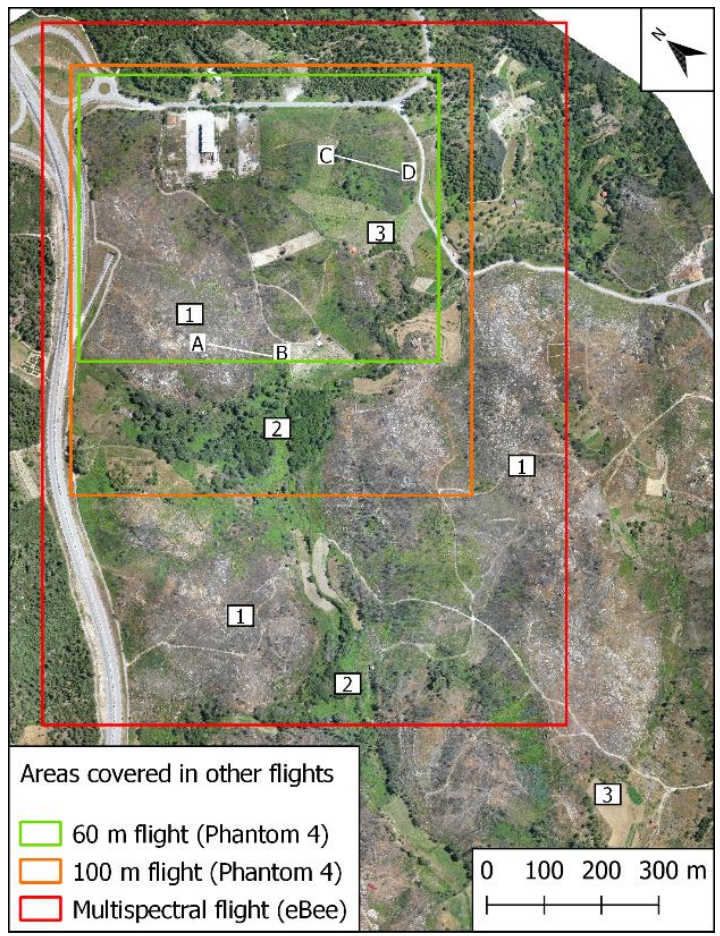

Figure 2. Orthophoto mosaic of the whole study area. Coloured rectangles represent the various flights carried out for different purposes. The numbers refer to: (1) logging operations; (2) trees that were not affected by the fire; and (3) agricultural fields. Lines A-B and C-D represent the profile lines used in this study.

Regarding the NDVI resultant from the multispectral flight it is presented in Figure 3a. The NDVI was used to assess the fire severity and restauration of the burned area, as shown in Figure $3 \mathrm{~b}$. This process was achieved by using a $10 \mathrm{~m}$ grid to obtain the mean NDVI value, then it was classified in three classes: low, considering values lower or equal than 0.5 ; medium, considering values greater than 0.5 and lower than 0.7 ; and high, for values greater than 0.7 .

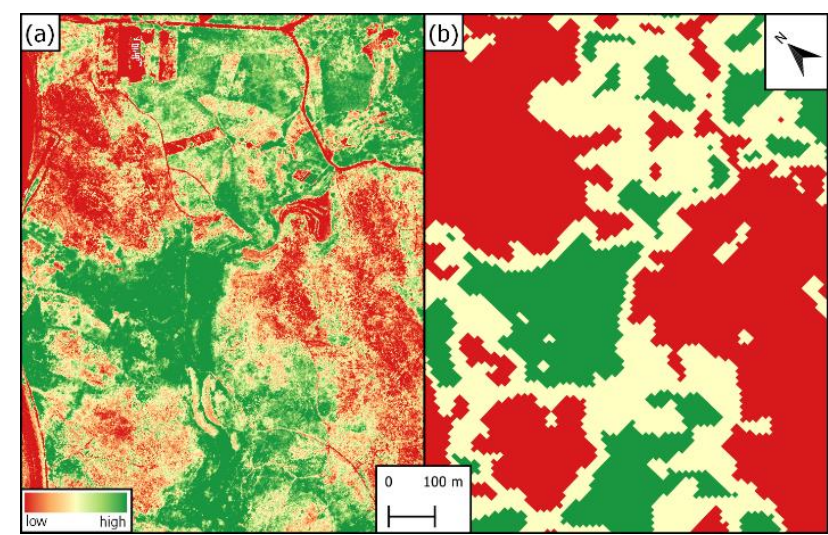

Figure 3. Colour coded NDVI map of the surveyed area (a) and its smoothed three-class NDVI map.

By analysing the smoothed three-class NDVI map for the whole 160 ha covered, it is observed that $45 \%$ of the area was classified as low ( 72 ha), $34 \%$ as medium ( 55 ha) and $21 \%$ as high ( 33 ha). This behaviour was expected since the period from the fire disturbance is approximately two years. Areas classified in the low class are mostly non-vegetated areas, composed of bare soil coinciding, and areas where logging operations took place and where there are some dead trees. In turn, areas classified in the medium class were mainly composed of low-vegetation and some agricultural fields, while high class is mainly composed of trees not/barely affected by the fire, shrubs, agricultural crops and pasture fields.

As for the three-dimensional characterization of the study area, two profile lines were used (A-B and C-D lines in Figure 2) and the DSM and CHM from the three RGB flights were evaluated. The profiles were located in a non-vegetated area (profile A-B) and in an area with live and dead trees (profile C-D). Figure 4 presents these results. Profile lines were used by Aicardi et al. (2016) to assess post-fire forestry regeneration using multitemporal data.
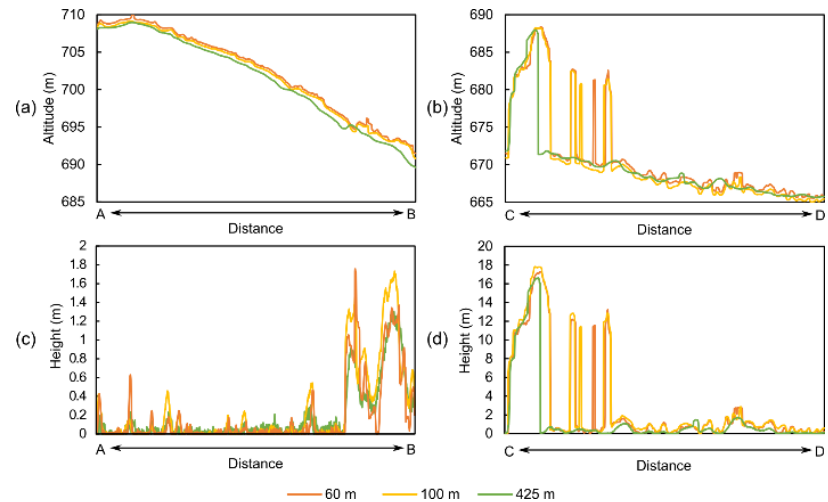

Figure 4. Altitude ( $a$ and $b$ ) and height ( $c$ and d) from two profile lines of DSMs and CHMs of the three RGB flights.

When analysing the DSM and CHM in the profile line A-B (Figure $4 \mathrm{a}$ and $\mathrm{c}$ ) it is verified that the flight conducted at $425 \mathrm{~m}$ height shown lower altitude in the DSM and a smoother CHM, which was not verified in both flights performed at lower flight height $(100 \mathrm{~m}$ and $60 \mathrm{~m}$ ). Regarding the profile line C-D (Figure $4 \mathrm{~b}$ and d) more details in the height of dead trees are observed in the $60 \mathrm{~m}$ flight height, while the flight at 425 height showed height information in the trees with foliage while, missing completely the height information for the dead trees. These results are directly related with the GSD of the imagery since both flights performed by the multi-rotor UAV have a GSD lower 
than $5 \mathrm{~cm}$ while the fixed-wing UAV has a GSD of $12 \mathrm{~cm}$. GSD values greater than $10 \mathrm{~cm}$ shown to be able to automatically detect and segment trees with leaves using CHMs and orthophoto mosaics (Marques et al., 2019).

When crossing the three-class NDVI with the CHMs of each flight (Table 2) a correlation is verified in all flights: the lower class has a mean height of $0.3 \mathrm{~m}$; a growth of the height is verified in the medium and high classes; and higher mean height values are verified in flights with greater spatial resolution.

\begin{tabular}{|c|c|c|c|c|}
\hline \multicolumn{2}{|c|}{ Flight height (m) } & 425 & 100 & 60 \\
\hline \multicolumn{2}{|c|}{ GSD (cm) } & 12 & 4.5 & 3 \\
\hline \multirow{2}{*}{$\begin{array}{c}\text { NDVI class } \\
\text { (mean value) }\end{array}$} & Low (0.33) & 0.3 & 0.3 & 0.3 \\
\cline { 2 - 5 } & Medium (0.61) & 1.5 & 1.8 & 1.9 \\
\cline { 2 - 5 } & High (0.78) & 2.4 & 4.0 & 4.4 \\
\hline
\end{tabular}

Table 2. Mean NDVI and height values for low, medium and high classes of the tree-classes NDVI, in each performed flight.

The height of the 35 trees measured in the field enabled to compare the produced CHMs of the flights conducted at $100 \mathrm{~m}$ and $60 \mathrm{~m}$, the CHM of the flight conducted at $425 \mathrm{~m}$ height was discarded from this evaluation due to the poor results observed in burned trees, as shown in Figure 5.

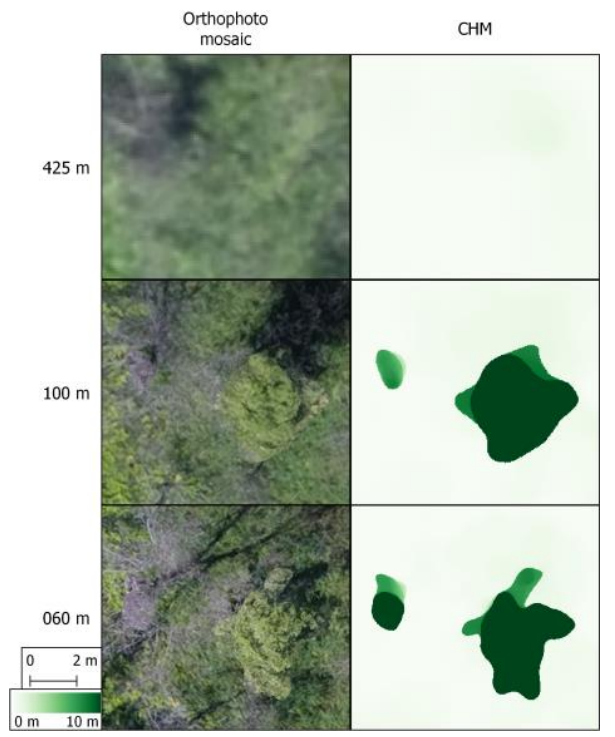

Figure 5. Details of the orthophoto mosaics and canopy height models computed from the UAV-based imagery acquired at different flight heights in a burned and in a regenerated tree.

The measured trees have a mean height of $12.7 \mathrm{~m}$ and ranged from $9.1 \mathrm{~m}$ to $16.7 \mathrm{~m}$. The estimated height values of the $100 \mathrm{~m}$ flight ranged between $1.8 \mathrm{~m}$ and $17.2 \mathrm{~m}$ with a mean of $8.1 \mathrm{~m}$. As for the $60 \mathrm{~m}$ flight those ranged from $6.3 \mathrm{~m}$ to 14.3 being its mean value $11.1 \mathrm{~m}$. These results are presented in Table 3 . Overall, it can be stated that the flight conducted at $60 \mathrm{~m}$ height better describes the observed tree height providing higher $R^{2}$ values and lower RMSE values. The better correlation was achieved in trees not affected by the fire. A good correlation was obtained in the burned trees but with a RMSE of 4.5 meters which can be explained by the photogrammetric processing which resulted in the removal of leafless branches presenting only the tree trunk that allied to the process of point cloud interpolation and noise removal can cause a smoothing effect of the generated raster information (see Figure 5), another aspect that should be considered is the increasing of imagery overlap, in Carr and
Slyder (2018) both forward and side overlap were set to $90 \%$ for individual leaf-off tree segmentation using point clouds in flight heights of $80 \mathrm{~m}$ and $100 \mathrm{~m}$. As for the trees partially affected by the fire, obtained the lower correlation value but an RMSE of 1.1 m. Nevertheless, these results are in line with studies that assessed leaf-on and leaf-off tree height (Imangholiloo et al., 2019).

\begin{tabular}{|c|c|c|c|}
\hline \multicolumn{2}{|c|}{ Flight height (m) } & 100 & 60 \\
\hline \multicolumn{2}{|c|}{ GSD (cm) } & 4.5 & 3 \\
\hline \multirow{2}{*}{ Not affected } & $R^{2}$ & 0.2 & 0.8 \\
\cline { 2 - 4 } & RMSE (m) & 2.4 & 1.0 \\
\hline \multirow{2}{*}{ Partially burned } & $R^{2}$ & 0.2 & 0.5 \\
\cline { 2 - 4 } & RMSE (m) & 3.7 & 1.1 \\
\hline \multirow{2}{*}{ Burned } & $R^{2}$ & 0.2 & 0.6 \\
\cline { 2 - 4 } & RMSE (m) & 8.6 & 4.5 \\
\hline
\end{tabular}

Table 3. Results from the coefficient of determination $\left(R^{2}\right)$ and root mean square error (RMSE) for the $100 \mathrm{~m}$ and 60 $\mathrm{m}$ flight height flights in each tree type and the overall value.

\section{CONCLUSIONS}

This study shows the suitability of UAVs to survey post-fires areas using RGB and multispectral imagery. While RGB imagery enables the visual assessment of the area, the usage of the vegetation indices, such as NDVI, enable to characterize vegetation regeneration in the study area. Moreover, the photogrammetric processing of lower altitude RGB flights provided a more detailed $3 \mathrm{D}$ characterization of the area. This way, UAVs poses as a tool to help foresters in data post-fire data acquisition, reducing costs and saving time when compared to traditional field surveys.

Multi-temporal observations of this type of disturbances using UAV-based imagery poses as a way to effectively analyse forestry regeneration to fires and to follow management activities. As such, future work will focus in multi-temporal acquisition UAV-based imagery to assess post-fire forestry recovery. Moreover, the development of methods for automatic monitoring of post-fire scenarios as to be considered, providing easier and rapid ways towards this task. This way, segmenting trees and snags to estimate biomass to be logged and to assess tree health condition through multispectral data.

\section{ACKNOWLEDGEMENTS}

The research activities of Luís Pádua were funded by the Portuguese Science Foundation (SFRH/BD/139702/2018).

\section{REFERENCES}

Aicardi, I., Garbarino, M., Lingua, A., Lingua, E., Marzano, R., Piras, M., 2016. Monitoring Post-Fire Forest Recovery Using Multitemporal Digital Surface Models Generated from Different Platforms. Earsel Eproceedings 15, 1-8.

Camia, A., Liberta, G., San-Miguel-Ayanz, J., 2017. Modeling the impacts of climate change on forest fire danger in Europe. EU JRC Tech Rep 1-22.

Carr, J.C., Slyder, J.B., 2018. Individual tree segmentation from a leaf-off photogrammetric point cloud. Int. J. Remote Sens. 39, 5195-5210. https://doi.org/10.1080/01431161.2018.1434330 Carvajal-Ramírez, F., Marques da Silva, J.R., Agüera-Vega, F., Martínez-Carricondo, P., Serrano, J., Moral, F.J., 2019. Evaluation of Fire Severity Indices Based on Pre- and Post-Fire Multispectral Imagery Sensed from UAV. Remote Sens. 11, 993. https://doi.org/10.3390/rs11090993 
Chu, T., Guo, X., 2014. Remote Sensing Techniques in Monitoring Post-Fire Effects and Patterns of Forest Recovery in Boreal Forest Regions: A Review. Remote Sens. 6, 470-520. https://doi.org/10.3390/rs6010470

Clemente, R.H., Cerrillo, R.M.N., Gitas, I.Z., 2009. Monitoring post-fire regeneration in Mediterranean ecosystems by employing multitemporal satellite imagery. Int. J. Wildland Fire 18, 648-658. https://doi.org/10.1071/WF07076

Dale, V.H., Joyce, L.A., McNulty, S., Neilson, R.P., Ayres, M.P., Flannigan, M.D., Hanson, P.J., Irland, L.C., Lugo, A.E., Peterson, C.J., Simberloff, D., Swanson, F.J., Stocks, B.J., Wotton, B.M., 2001. Climate Change and Forest DisturbancesClimate change can affect forests by altering the frequency, intensity, duration, and timing of fire, drought, introduced species, insect and pathogen outbreaks, hurricanes, windstorms, ice storms, or landslides. BioScience 51, 723-734. https://doi.org/10.1641/0006-

3568(2001)051[0723:CCAFD]2.0.CO;2

Eidenshink, J., Schwind, B., Brewer, K., Zhu, Z.-L., Quayle, B., Howard, S., 2007. A Project for Monitoring Trends in Burn Severity. Fire Ecol. 3, 3-21. https://doi.org/10.4996/fireecology.0301003

Fernández-Álvarez, M., Armesto, J., Picos, J., 2019. LiDARBased Wildfire Prevention in WUI: The Automatic Detection, Measurement and Evaluation of Forest Fuels. Forests 10, 148. https://doi.org/10.3390/f10020148

Fernández-Guisuraga, J.M., Sanz-Ablanedo, E., Suárez-Seoane, S., Calvo, L., 2018. Using Unmanned Aerial Vehicles in Postfire Vegetation Survey Campaigns through Large and Heterogeneous Areas: Opportunities and Challenges. Sensors 18, 586 https://doi.org/10.3390/s18020586

Foster, D.R., Knight, D.H., Franklin, J.F., 1998. Landscape Patterns and Legacies Resulting from Large, Infrequent Forest Disturbances. Ecosystems 1, 497-510. https://doi.org/10.1007/s100219900046

Fraser, R.H., Van der Sluijs, J., Hall, R.J., 2017. Calibrating Satellite-Based Indices of Burn Severity from UAV-Derived Metrics of a Burned Boreal Forest in NWT, Canada. Remote Sens. 9, 279. https://doi.org/10.3390/rs9030279

Imangholiloo, M., Saarinen, N., Markelin, L., Rosnell, T., Näsi, R., Hakala, T., Honkavaara, E., Holopainen, M., Hyyppä, J., Vastaranta, M., 2019. Characterizing Seedling Stands Using Leaf-Off and Leaf-On Photogrammetric Point Clouds and Hyperspectral Imagery Acquired from Unmanned Aerial Vehicle. Forests 10, 415. https://doi.org/10.3390/f10050415 Larrinaga, A.R., Brotons, L., 2019. Greenness Indices from a Low-Cost UAV Imagery as Tools for Monitoring Post-Fire Forest Recovery. Drones 3, 6 . https://doi.org/10.3390/drones3010006

Lentile, L.B., Holden, Z.A., Smith, A.M.S., Falkowski, M.J., Hudak, A.T., Morgan, P., Lewis, S.A., Gessler, P.E., Benson, N.C., 2006. Remote sensing techniques to assess active fire characteristics and post-fire effects. Int. J. Wildland Fire 15, 319345. https://doi.org/10.1071/WF05097

Marques, P., Pádua, L., Adão, T., Hruška, J., Peres, E., Sousa, A., Sousa, J.J., 2019. UAV-Based Automatic Detection and Monitoring of Chestnut Trees. Remote Sens. 11, 855. https://doi.org/10.3390/rs11070855

Martínez-de Dios, J.R., Merino, L., Caballero, F., Ollero, A., 2011. Automatic forest-fire measuring using ground stations and Unmanned Aerial Systems. Sensors 11, 6328-6353. https://doi.org/10.3390/s110606328

McKenna, P., Erskine, P.D., Lechner, A.M., Phinn, S., 2017. Measuring fire severity using UAV imagery in semi-arid central Queensland, Australia. Int. J. Remote Sens. 38, 4244-4264. https://doi.org/10.1080/01431161.2017.1317942
Merino, L., Caballero, F., Martínez-de-Dios, J.R., Maza, I., Ollero, A., 2012. An Unmanned Aircraft System for Automatic Forest Fire Monitoring and Measurement. J. Intell. Robot. Syst. 65, 533-548. https://doi.org/10.1007/s10846-011-9560-x

Ni, W., Dong, J., Sun, G., Zhang, Z., Pang, Y., Tian, X., Li, Z., Chen, E., 2019. Synthesis of Leaf-on and Leaf-off Unmanned Aerial Vehicle (UAV) Stereo Imagery for the Inventory of Aboveground Biomass of Deciduous Forests. Remote Sens. 11, 889. https://doi.org/10.3390/rs11070889

Pádua, L., Vanko, J., Hruška, J., Adão, T., Sousa, J.J., Peres, E., Morais, R., 2017. UAS, sensors, and data processing in agroforestry: a review towards practical applications. Int. J. Remote Sens. 38, 2349-2391. https://doi.org/10.1080/01431161.2017.1297548

Popescu, S.C., 2007. Estimating biomass of individual pine trees using airborne lidar. Biomass Bioenergy, Multiple benefits from sustainable bioenergy systemsProceedings of a Joint Workshop of IEA Bioenergy Task 30 and Task 31, August 2005, Perth, Western Australia, IEA Bioenergy T31:2007:01 31, 646-655. https://doi.org/10.1016/j.biombioe.2007.06.022

Rouse, J.W., Jr., Haas, R.H., Schell, J.A., Deering, D.W., 1974. Monitoring Vegetation Systems in the Great Plains with Erts. NASA Spec. Publ. 351, 309.

Seidl, R., Thom, D., Kautz, M., Martin-Benito, D., Peltoniemi, M., Vacchiano, G., Wild, J., Ascoli, D., Petr, M., Honkaniemi, J., Lexer, M.J., Trotsiuk, V., Mairota, P., Svoboda, M., Fabrika, M., Nagel, T.A., Reyer, C.P.O., 2017. Forest disturbances under climate change. Nat. Clim. Change 7, 395-402. https://doi.org/10.1038/nclimate3303

Shin, P., Sankey, T., Moore, M.M., Thode, A.E., 2018. Evaluating Unmanned Aerial Vehicle Images for Estimating Forest Canopy Fuels in a Ponderosa Pine Stand. Remote Sens. 10, 1266. https://doi.org/10.3390/rs10081266

Torresan, C., Berton, A., Carotenuto, F., Gennaro, S.F.D., Gioli, B., Matese, A., Miglietta, F., Vagnoli, C., Zaldei, A., Wallace, L., 2017. Forestry applications of UAVs in Europe: a review. Int. J. Remote Sens. 38, 2427-2447. https://doi.org/10.1080/01431161.2016.1252477

Van Leeuwen, W.J.D., 2008. Monitoring the Effects of Forest Restoration Treatments on Post-Fire Vegetation Recovery with MODIS Multitemporal Data. Sensors 8, 2017-2042. https://doi.org/10.3390/s8032017

White, R.A., Bomber, M., Hupy, J.P., Shortridge, A., 2018. UASGEOBIA Approach to Sapling Identification in Jack Pine Barrens after Fire. Drones 2, 40. https://doi.org/10.3390/drones2040040

Yuan, C., Zhang, Y., Liu, Z., 2015. A survey on technologies for automatic forest fire monitoring, detection, and fighting using unmanned aerial vehicles and remote sensing techniques. Can. J. For. Res. 45, 783-792. https://doi.org/10.1139/cjfr-2014-0347 